\title{
Distribution of Lettuce Big-Vein Incidence Under Three Irrigation Systems
}

\author{
J. J. Hao, School of Food and Agriculture, University of Maine, Orono 04469-5735; and K. V. Subbarao, Department of Plant \\ Pathology, University of California, Davis, c/o U.S. Agricultural Research Station, Salinas, CA 93905
}

\begin{abstract}
Hao, J. J., and Subbarao, K. V. 2014. Distribution of lettuce big-vein incidence under three irrigation systems. Plant Dis. 98:206-212.

Spatial patterns of lettuce big-vein (LBV) incidence under furrow, sprinkler, and subsurface drip irrigation systems were determined. Because LBV pathogen is a virus and is vectored by the soilborne chytrid Olpidium brassicae, different irrigation systems likely affect the movement of the vector and were hypothesized to result in different distribution patterns and levels of the disease. Lettuce plants were mapped by recording the location of each LBV-infected or healthy plant in arbitrarily selected plots of sizes 16 by 30,20 by 30 , and 18 by $50 \mathrm{~m}$ in Salinas, Gonzales, and Santa Maria in California. Data were arrayed into different quadrat sizes by rearrangement, and disease incidence was calculated for each quadrat. Frequency distribution analysis and spatial autocorrelation analyses were performed on this data. LBV incidence was aggregated in all furrow-irrigated fields, four

of five subsurface drip-irrigated fields, and two of three sprinkler-irrigated fields. The remaining fields had a random distribution. As the quadrat size increased, index of aggregation decreased, and vice versa. In fields under sprinkler irrigation, regardless of whether the spatial pattern of LBV was random or aggregated, no directional orientation occurred. However, under furrow or subsurface drip irrigation, the aggregation mostly occurred across the rows. Although irrigation type influenced LBV distribution pattern and incidence in lettuce fields, the differential effects of irrigation type on vector $O$. brassicae could not be discerned in this study. The sprinkler irrigation practiced in lettuce production until thinning may influence the vector distribution and the subsequent irrigation methods adapted for the remainder of the season in individual fields may play a significant role in disease incidence.
\end{abstract}

Big-vein is an economically damaging disease complex of lettuce (Lactuca sativa L.) that occurs worldwide $(9,11,19,21,23$, $31,32)$, and has been a problem for decades in California $(5-7,38)$. Infected lettuce plants with symptoms of vein banding on leaves show delays in plant maturity and reduction in market value $(7,34)$. The disease-causing agent is Mirafiori lettuce big-vein virus (MLBVV), which is vectored by the soilborne chytrid Olpidium brassicae (23,31). Although genetic resistance from $L$. virosa offers an effective and economically feasible method of controlling big-vein $(14,15)$, only partial resistance exists in cultivated lettuce $(2,11,21,34)$.

$O$. brassicae individuals carry MLBVV within their zoospores, which attach and infect host roots. The virus survives within the resting sporangia of $O$. brassicae and persists under adverse soil conditions for more than 10 years (5), enabling MLBVV to spread between crops and survive between seasons. Eventually, all fields could be infested with MLBVV given the extensive movement of equipment and personnel in production fields. Once the soil gets infested with MLBVV, it is difficult to control the lettuce big-vein (LBV) disease. Thus, methods to control LBV have focused on controlling or reducing survival of $O$. brassicae $(7,39)$.

Soil temperature and moisture are important factors for the growth of $O$. brassicae and the expression of disease $(6,7,38,39)$. Despite the vector being ubiquitous in California, growers have long noticed that the disease is more severe in sprinkler-irrigated fields than in fields with other irrigation types. We hypothesized that the different irrigation systems may influence the movement of the vector, $O$. brassicae, and this then can affect the distribution of LBV disease in a given field. The irrigation methods can also differentially redistribute the pathogen with the move-

Corresponding author: K. V. Subbarao, E-mail: kvsubbarao@ucdavis.edu

Current address of J. J. Hao: School of Food and Agriculture, University of Maine, Orono 04469-5735.

Accepted for publication 22 August 2013.

http://dx.doi.org/10.1094/PDIS-04-13-0410-RE

(C) 2014 The American Phytopathological Society ment of water and result in different patterns of disease in the field.

In contrast to the advancements made on the pathogen biology and etiology of the disease (35), very little quantitative information is available on the spread of the disease under varying irrigation practices and the patterns of disease these establish. Analysis of spatial patterns provides a better understanding of the pathogen dispersal $(3,12,22,29)$, disease development $(7,27,28)$, vector dynamics (26), and choice of sampling procedures (24). A number of techniques have been employed in spatial pattern analyses $(4,17,25,29)$ and many are widely applied in plant pathology $(8,20,22,26,28,41)$. For example, index of dispersion $(D)$ is a simple parameter used to determine spatial patterns (16). The $\beta$-binomial distribution, which accounts for the binary properties of disease incidence, has been described in depth and proven theoretically for use in plant disease distribution studies $(16,17,24,25)$. The spatial dependence among neighboring plants or pathogen propagules can be determined by autocorrelation. Geostatistics has been successfully employed in plant pathology to create geospatial information about diseases $(8,10,18,20,22)$. It detects spatial dependence in all directions by measuring the variation among samples (or quadrats in most studies, including this one) separated by the same distance (10). These techniques were employed to outline the spatial pattern attributes of LBV disease in our analytical work.

The purpose of this study was to determine the spread of LBV disease as influenced by three irrigation systems, and from the patterns of disease observed, to infer information on the movement of the vector. Preliminary results from this study have been published previously (13).

\section{Materials and Methods}

Field locations and data collection. Between 1995 and 1997, 14 commercial fields of crisphead lettuce were selected in the Salinas and Santa Maria Valleys in California (Table 1). These fields represented three irrigation systems prevalent during that time and had symptomatic LBV plants at near-harvest maturity. In each field, one or more plots of varying sizes were arbitrarily chosen for LBV incidence evaluation (Table 1). The plot size was either 16 by 30,10 by 50 , or 18 by $50 \mathrm{~m}$, depending on the location. All the selected fields were direct seeded and irrigated with sprinklers until 
thinning stage (a standard practice for lettuce production). Subsequently, individual fields were irrigated by one of three methods: furrow, sprinkler, or subsurface drip, with the exception of field SPK01 (Table 1), in which furrow and sprinkler were used alternately throughout the entire season. Although the frequency of irrigation varied by the type, the total irrigation water applied for each crop was nearly identical (40). Fields were prepared and cultivated by growers using best management practices (37). All fields were planted in two-row beds, with approximately 25 to $33 \mathrm{~cm}$ between plants and $40 \mathrm{~cm}$ between plant rows within a bed. Approximately 2 to 3 weeks prior to harvest, the fields were mapped by recording the location of each plant and whether the plant was healthy or diseased.

Spatial pattern analyses. Data collected from the fields were rearranged to provide contiguous quadrats or sampling units, from 0.5 by 1 to 4 by $8 \mathrm{~m}$, in the directions of across rows and within rows, respectively. A quadrat size of 2 by $2 \mathrm{~m}$ was used throughout the analyses unless other quadrat sizes are mentioned. Because missing plants in the plots were rare and the disease incidence was relatively low, locations without plants were arbitrarily counted as healthy plants. Therefore, the number of plants in each quadrat was considered equal. The incidence of LBV was estimated as the expected probability of diseased plants $(P)$. The data were analyzed using point pattern analysis (24-26) and geostatistics (18). The data were also analyzed using programs such as BBD (24), LCOR2 (12), and VARIOWIN (30). BBD is a computer program that provides several indices of aggregation and goodness-of-fit for $\beta$-binomial distribution for binary data such as disease incidence (25). Using maximum likelihood, the disease incidence was evaluated for over dispersion. The $\beta$-binomial distribution $\theta$ can be used as an index of aggregation to test the heterogeneity of incidence. Larger $\theta$ and smaller standard errors (se) associated with $\theta$ indicate an aggregated disease pattern. When $\theta$ is 0 , the pattern tends to be random or have a binomial distribution. A $t$ test $[t=\theta / \operatorname{se}(\theta)]$ was performed to test the significance (25). When $\theta=0$, the null hypothesis $H_{0}(\theta=0)$ was not rejected because the distribution was random. In addition to $\theta$ value, $D$, and Neyman's $C(\alpha)$ were calculated as the aggregation estimates. Distribution is aggregated when $D>1$ and random or uniform when $D \leq 1$. The parameters described above were calculated using the BBD computer program (16). Because the data array in the BBD program is limited to 500 sample units, all data sets were truncated to fit this requirement by selecting 500 quadrats from the center of each plot, if necessary.

Autocorrelation was used to examine the dependence of disease in quadrats as the lag distance increased. A high correlation coefficient indicates a spatial correlation or dependence of disease between quadrats. LCOR2 computer program was used to determine the autocorrelation of disease incidence among the quadrats (13). This program provides autocorrelation coefficients (RHO-BAR), and correlation coefficients (RHO-PLUS and RHO-MINUS) representing effects of disease in the two diagonal directions.

Geostatistical analysis creates and interprets continuous quantitative data by using parameters such as semivariance and correla- tion coefficient. Semivariance, $v(h)$, is the key parameter, and it is defined as the variance about the average of the squared differences in values between pairs of samples separated by distance $(h)$. Variogram is a graphic plot of $v(h)$ versus distance $h$. More importantly, this method can calculate the parameters for all directions. If the incidence of disease is spatially dependent, $v(h)$ is positively correlated with $h$ with a linear relationship. Theoretically, it can detect the spatial dependence in any direction. The potential anisotropic patterns in four directions with $22.5^{\circ}$ direction tolerance- $0^{\circ}$ (within rows), $90^{\circ}$ (across rows), and $45^{\circ}$ and $135^{\circ}$ (diagonal directions) - were also determined. Maps of spatial patterns were created using the DMAP program (unpublished data).

\section{Results}

Point pattern analysis of $\mathbf{L B V}$ incidence. The incidence of LBV varied from 3 to $33 \%$, with averaged incidence of 17,16 , and $11 \%$ under sprinkler, subsurface drip, and furrow irrigation, respectively. Overall incidence of LBV was not significantly different between irrigation types (Table 2$)$. An intracluster correlation $(\rho=$ $\theta /[1+\theta])$ plotted against $P$ on a $\log$ scale demonstrated no significant correlation (0.02) between degree of aggregation and disease incidence. The analyses were performed with data arrayed in a 2by-2-m quadrat size (Fig. 1). Index of aggregation $(\theta)$ varied from 0.007 to 0.05 (Table 2). For sprinkler irrigation, $\theta$ from two fields (GZL01 and GZL02) was not >0, suggesting a random distribution, and $\theta$ from one field (GZL03) was $>0$, indicating an aggregated distribution. Two subsurface drip-irrigated fields (BLC02 and HIT03) showed a random distribution $(\theta$ was not $>0)$, and three fields (BLC01, HIT01, and HIT02) had an aggregated distribution $(\theta>0)$. All six fields evaluated under furrow irrigation had $\theta>0$, indicating an aggregated pattern. $D$ was significantly $>1$ in 12 fields, suggesting an aggregated pattern, and $D=1$ in two fields (GZL01 and HIT03; Table 2). The patterns derived from the $Z$ statistic associated with the Neyman's $C(\alpha)$ test was identical to that from $D$. The pattern of LBV overall in the fields was more aggregated under furrow irrigation and less aggregated under sprinkler irrigation.

The value of $\theta$ from the $\beta$-binomial distribution analysis varied depending on the quadrat size. In general, as the quadrat size increased, the value of $\theta$ approached zero. This suggested that quadrat sizes affected the results from the spatial pattern analyses and, when the size of quadrats was increased, the pattern approximated a random distribution (Fig. 2). In field GZL02 that was sprinkler irrigated (Fig. 2A-s), $\theta$ was small for quadrat sizes from 1 to $4 \mathrm{~m}$ across rows and 1 to $8 \mathrm{~m}$ within rows; $\theta$ was large only when quadrat size was $0.5 \mathrm{~m}$ across rows or $1 \mathrm{~m}$ within rows. In both HIT01, a subsurface-irrigated field (Fig. 2B-d), and LPC01 (Fig. 2C-f), a furrow-irrigated field, $\theta$ was smaller when quadrat size was larger than 1 by $1 \mathrm{~m}$. In field SPK01, a sprinkler- and furrow-irrigated field, $\theta$ was less affected close to 0 from 0.5 to $4 \mathrm{~m}$ across rows and 5 to $8 \mathrm{~m}$ within rows (Fig. 2D-sf).

Autocorrelation. For LBV incidence in the fields with sprinkler (Fig. 3A-s) and with a combination of sprinkler and furrow irriga-

Table 1. Commercial lettuce fields in California used for disease spatial pattern analyses on lettuce big-vein

\begin{tabular}{llclc}
\hline Field code & Location & Plot size $(\mathbf{m})$ & Irrigation type & Observation date \\
\hline GZL01 & Gonzales & 16 by 30 & Sprinkler & 31 May 1996 \\
GZL02 & Gonzales & 16 by 30 & Sprinkler & 31 May 1996 \\
GZL03 & Gonzales & 16 by 30 & Sprinkler & 24 June 1996 \\
BLC01 & Salinas & 20 by 50 & Subsurface drip & 24 August 1995 \\
BLC02 & Salinas & 20 by 50 & Subsurface drip & 26 August 1995 \\
HIT01 & Salinas & 20 by 30 & Subsurface drip & 10 May 1996 \\
HIT02 & Salinas & 20 by 30 & Subsurface drip & 10 May 1996 \\
HIT03 & Salinas & 20 by 30 & Subsurface drip & 16 September 1996 \\
LPC01 & Lompoc & 20 by 30 & Furrow & 14 July 1997 \\
LPC02 & Lompoc & 20 by 30 & Furrow & 14 July 1997 \\
LPC03 & Lompoc & 20 by 30 & Furrow & 15 July 1997 \\
SPK01 & Salinas & 20 by 30 & Furrow + sprinkler & 11 July 1996 \\
STM01 & Santa Maria & 18 by 50 & Furrow & 7 June 1995 \\
STM02 & Santa Maria & 18 by 50 & Furrow & 6 June 1995 \\
\hline
\end{tabular}


tions (SPK01, data not shown), there was no significant correlation between quadrats either along, across, or in diagonal directions of rows. For subsurface-drip irrigation, however, disease incidence was positively correlated within one quadrat in HIT01, within two quadrats in BLC02, and within all quadrats in BLC01 along the row. However, there was no correlation between LBV incidence across rows, such as in HIT03 (Fig. 3B-d), suggesting that there was no aggregated pattern in the two sprinkler-irrigated fields. For furrow-irrigated fields, the pattern was less aggregated, and aggregation, if there was any, occurred across rows. For furrowirrigated fields, such as LPC02 (Fig. 3C-f), LBV incidence was positively correlated within at least four quadrats along rows but no correlation was detected in the other directions, with some exceptions. For example, for LPC01, SPK01, and STM02, there was no correlation in any of the directions, suggesting an aggregated pattern across rows in furrow-irrigated fields. Results from all 14 plots showed that RHO-PLUS and RHO-MINUS correlation coefficients did not decrease at different rates over the spatial lags, indicating that disease incidence pattern relative to the rows was not skewed.

Geostatistical analysis on the spatial pattern of $\mathrm{LBV}$ incidence. Different patterns of LBV incidence under three different irrigation systems were detected using geostatistics (Fig. 4). For a sprinkler irrigation system, anisotropy was not detected (Fig. 4A1$\mathrm{s}$ and $\mathrm{A} 2-\mathrm{s})$, except in one field where semivariance had an increase at $45^{\circ}$ and $135^{\circ}$ at $6 \mathrm{~m}$, which was not stable after $8 \mathrm{~m}$ (Fig.

Table 2. Statistics describing spatial patterns of lettuce big-vein incidence in California with quadrat sizes of 2 by $2 \mathrm{~m}$ resulted from BBD program

\begin{tabular}{|c|c|c|c|c|c|c|c|c|c|}
\hline \multirow[b]{2}{*}{ Field } & \multirow[b]{2}{*}{ Irrigation type } & \multicolumn{4}{|c|}{$\beta$-Binomial parameter ${ }^{\mathbf{a}}$} & \multicolumn{4}{|c|}{ Homogeneity of variances ${ }^{b}$} \\
\hline & & $P$ & $\operatorname{se}(P)$ & $\theta$ & $\operatorname{se}(\theta)$ & $D$ & $P(D)$ & $Z$ & $P(Z)$ \\
\hline GZL01 & Sprinkler & 0.096 & 0.005 & 0.007 & 0.006 & 1.16 & 0.079 & 1.414 & 0.079 \\
\hline GZL02 & Sprinkler & 0.242 & 0.009 & 0.011 & 0.007 & 1.24 & $0.039 *$ & 1.820 & $0.034 *$ \\
\hline GZL03 & Sprinkler & 0.172 & 0.008 & 0.018 & $0.008 *$ & 1.41 & $0.002 *$ & 3.150 & $0.001^{*}$ \\
\hline BLC01 & Subsurface drip (Drip) & 0.287 & 0.008 & 0.050 & $0.008 *$ & 2.09 & $<0.001 *$ & 13.074 & $<0.001^{*}$ \\
\hline BLC02 & Drip & 0.333 & 0.033 & 0.008 & 0.006 & 1.76 & $<0.001^{*}$ & 9.261 & $<0.001^{*}$ \\
\hline HIT01 & Drip & 0.051 & 0.003 & 0.009 & $0.005^{*}$ & 1.18 & $0.030 *$ & 1.946 & $<0.026$ \\
\hline HIT02 & Drip & 0.024 & 0.002 & 0.011 & $0.006 *$ & 1.23 & $0.010^{*}$ & 2.446 & $0.007 *$ \\
\hline HIT03 & Drip & 0.127 & -1.000 & 0 & -1.000 & 1.00 & 0.490 & -0.095 & 1.000 \\
\hline LPC01 & Furrow & 0.146 & 0.008 & 0.027 & $0.008 *$ & 1.75 & $<0.001^{*}$ & 5.590 & $<0.001^{*}$ \\
\hline LPC02 & Furrow & 0.218 & 0 & 0.029 & $0.010 *$ & 1.81 & $<0.001 *$ & 5.660 & $<0.001^{*}$ \\
\hline LPC03 & Furrow & 0.092 & 0.006 & 0.027 & $0.007 *$ & 1.81 & $<0.001^{*}$ & 7.080 & $<0.001^{*}$ \\
\hline SPK01 & Furrow + sprinkler & 0.286 & 0.003 & 0.014 & $0.009 *$ & 1.33 & $0.005 *$ & 2.800 & $0.003^{*}$ \\
\hline STM01 & Furrow & 0.047 & 0.003 & 0.032 & $0.008 *$ & 1.79 & $<0.001 *$ & 9.310 & $<0.004$ \\
\hline STM02 & Furrow & 0.030 & 0.003 & 0.016 & $0.006 *$ & 1.35 & $<0.001^{*}$ & 3.970 & $<0.001^{*}$ \\
\hline
\end{tabular}

${ }^{a} P=$ expected probability of a plant exhibiting symptoms, estimated as the mean disease incidence; $\theta=$ index of aggregation; se $(x)=$ standard error of the estimated parameter $(x)$. Negative value for standard error indicates that maximum likelihood estimates were not obtained. A $t$ test was performed to examine whether it was binomial distribution $(\theta=0)$ or aggregated distribution $(\theta>0)$ at the significance level $(*) P<0.05$.

${ }^{\text {b }} D=$ index of dispersion, calculated as the ratio of observed variance/theoretical variance; $P(D)=$ probability of significance associated with $D$; * significance level is $0.05 ; Z=$ standard normal statistic of the $C(\alpha)$ test; $P(Z)=$ significance level of $Z$; and * significance level is 0.05 .

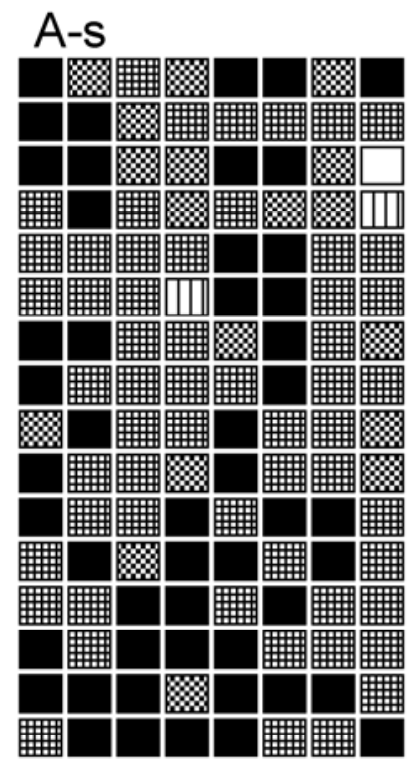

B-d

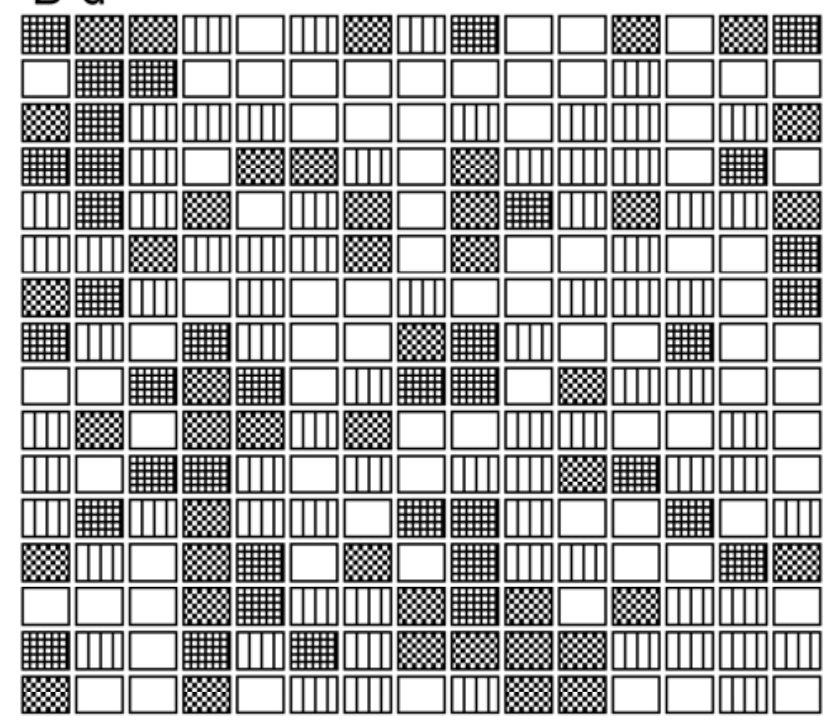

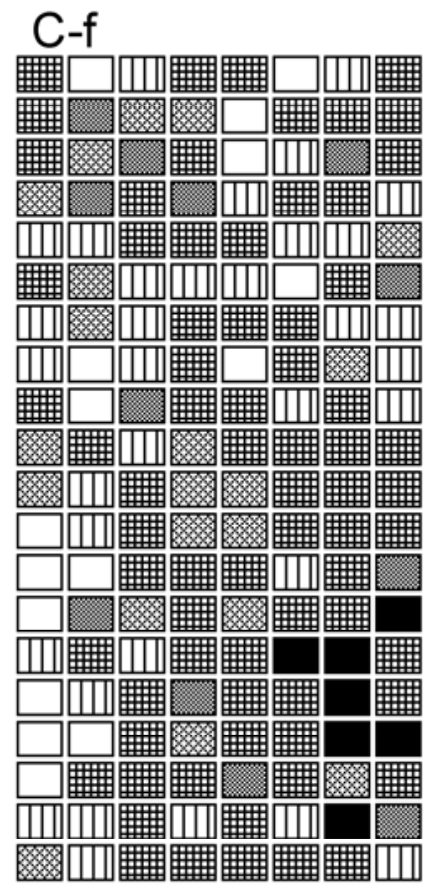

Disease incidence (\%)
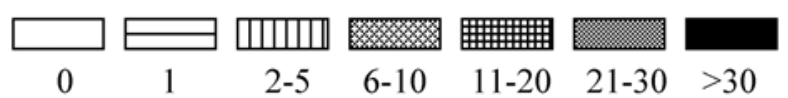

Fig. 1. Disease incidence maps of lettuce big-vein (LBV) under three representative irrigation systems in field plots. A-s, GZL02 was irrigated with sprinkler; B-d, HIT01 with subsurface drip; and C-f, LPC03 with furrow. All fields were irrigated with sprinklers until thinning. 
4A2-s). Semivariance increased after $10 \mathrm{~m}$ in the direction of $0^{\circ}$ (along the bed) and became irregular in the direction of $90^{\circ}$ (across the row). These results indicated that the spatial pattern of LBV incidence under sprinkler irrigation was not aggregated in most areas and the aggregation, if any, was irregular for all directions. For fields under subsurface irrigation, the semivariance did not change as the lag distance increased, indicating a lack of spatial dependence of disease incidence between quadrats (Fig. 4B1-d and B2-d). Variograms of disease incidence in furrow-irrigated fields (Fig. 4C1-f and C2-f) exhibited an anisotropic pattern. Semivariance in the direction of $90^{\circ}$ increased linearly in most of the observed plots and, occasionally, there was an increase in the direction of $135^{\circ}$ (Fig. 4C2-f). Semivariance increased across rows $\left(90^{\circ}\right)$ in all fields (Fig. 4C1-f and C2-f). In the direction of $0^{\circ}$ (within rows), no significant spatial correlation was detected. However, there was spatial dependence in the direction of $90^{\circ}$ (or across the rows). In other words, the spatial pattern of LBV incidence across the row was not evenly distributed.

\section{Discussion}

This study demonstrated that the three irrigation systems create different spatial patterns of LBV incidence, similar to that shown in disease systems such as lettuce drop (Sclerotinia minor) $(1,37)$ and Phytophthora blight of pepper (Phytophthora capsici) (3). Under sprinkler irrigation, the disease distribution was random; in subsurface drip-irrigated fields, it was both random and aggregated, with greater aggregation across the rows; and, in furrowirrigated fields, the disease exhibited an aggregated pattern. The degree of aggregation was affected by the quadrat sizes. LBV incidence tended to be aggregated as the quadrat size decreased and randomly or uniformly distributed as the quadrat size increased. The previously established patterns of big-vein disease in these fields likely also influenced the observed patterns of the disease but the effect of irrigation type within the season is highly relevant to the patterns observed regardless of history. Nonetheless, these
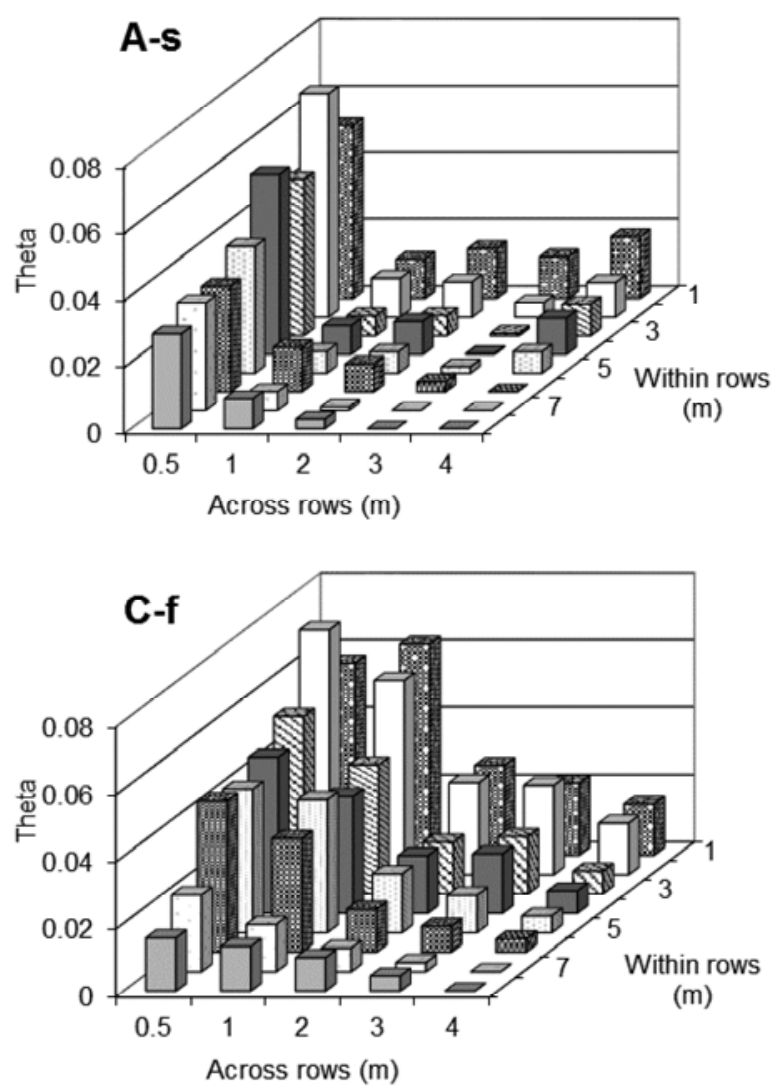

aWithin rows $\mathbf{a}$ Across rows
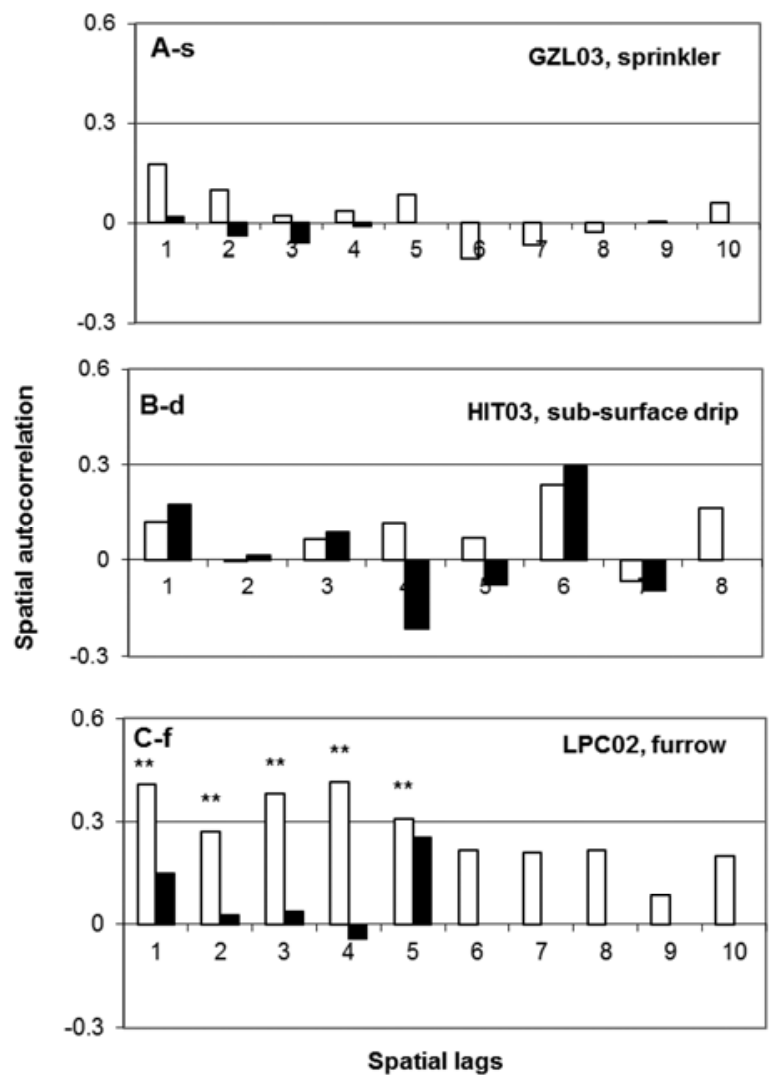

Fig. 3. Autocorrelation analyses on lettuce big-vein (LBV) incidence under three irrigation methods. A-s, GZL03 was sprinkler irrigated; B-d, HIT03 was subsurface drip irrigated; and C-f, LPC02 was furrow irrigated. Numbers below each column are number lags (number of distance units).
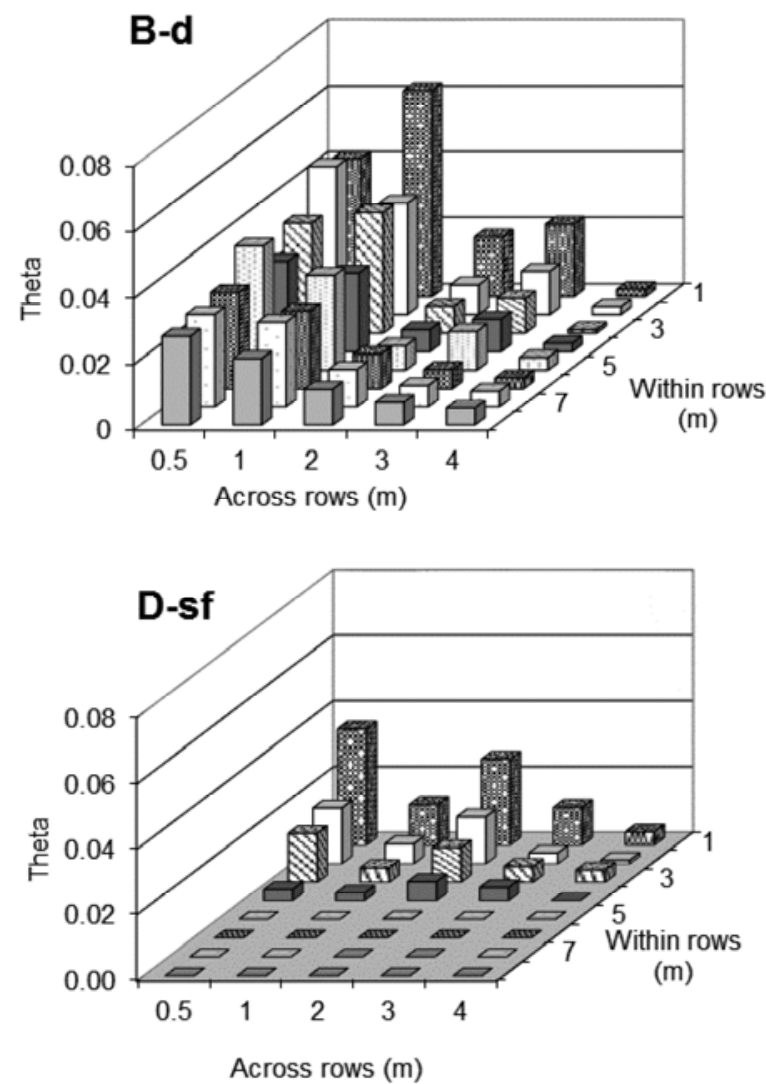

Fig. 2. Relationship between quadrat size and degree of aggregation ( $\theta$ ).A-s, GZL02 was sprinkler irrigated; B-d, HIT01 was subsurface drip irrigated; C-f, LPC01 was furrow irrigated; and D-sf, SPK01 was sprinkler and furrow irrigated. 
studies were conducted in commercial fields, and the many varying factors not considered in this study may also have influenced the results.

The incidence of LBV is determined by the soil population of $O$. brassicae, which vectors the virus causing LBV. It is assumed that $O$. brassicae is ubiquitous in lettuce fields in California and that the lettuce plants are infected only when soil conditions such as moisture and soil type are satisfied (5,6). It is evident that irrigation water provides the necessary conditions for the vector to produce zoospores, which then carry the big-vein virus into the plants. Therefore, the disease incidence pattern is expected to reflect the distribution of the vector and also the pattern of soil moisture.
Sprinkler irrigation is used in all lettuce production from planting to thinning to ensure seed germination and uniform seedling emergence (33) regardless of the irrigation methods adapted following thinning for the remainder of the season. Thus, irrigation methods play a significant role in the distribution of the LBV vector. Lettuce seedlings have fewer adventitious roots and a less welldeveloped tap root during the seedling stages (36), facilitating the attachment of the vector to the adventitious roots and delivering the virus to the tap root, increasing the likelihood of successful LBV infection of lettuce seedlings. Post thinning, a robust tap root with a network of adventitious roots develops in lettuce (36), increasing the probability of infection.

\section{Semivariogram}
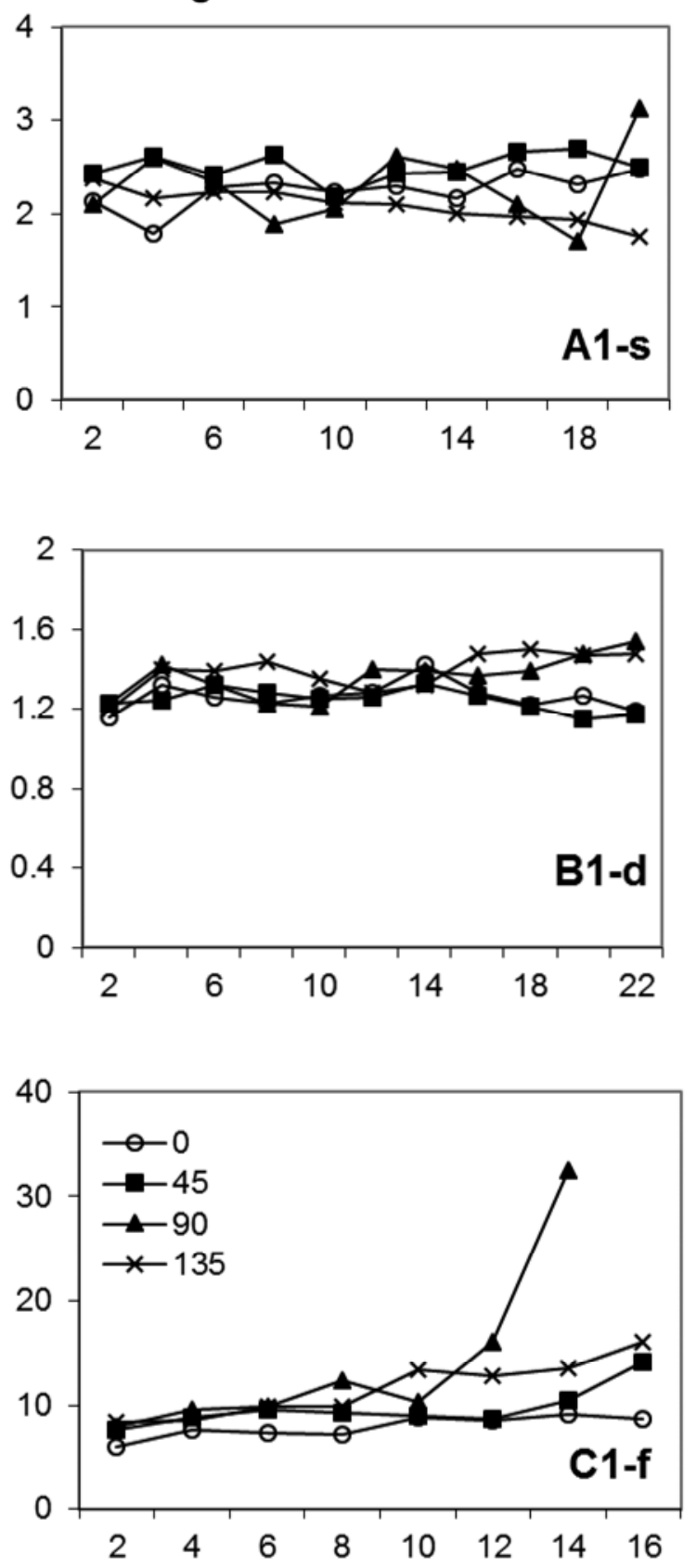
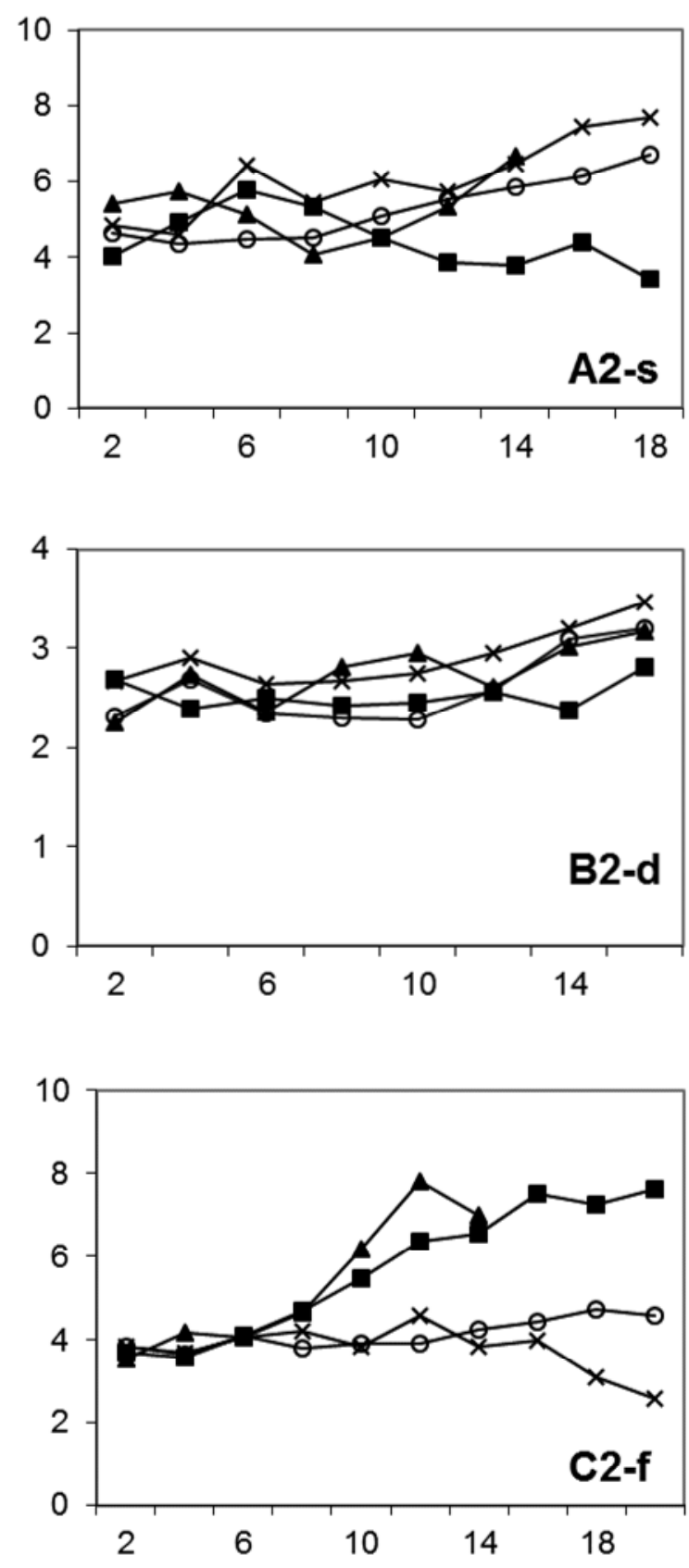

\section{Lag distance $(\mathrm{m})$}

Fig. 4. Variograms for lettuce big-vein (LBV) incidence under three irrigation methods. Directions are $0^{\circ}$ (within rows), $90^{\circ}$ (across rows), and $45^{\circ}$ and $135^{\circ}$ (diagonal). Selected fields represent three irrigation systems. A1-s, GZL01 and A2-s, GZL02 were irrigated with sprinkler; B1-d, HIT01 and B2-d, HIT2 were irrigated with subsurface drip; and C1-f, LPC02 and C2-f, LPC03 were irrigated with furrow. 
The three different irrigation systems studied here produce different moisture patterns. Furrow irrigation results in a uniform distribution of moisture through the soil profile from 5 to $15 \mathrm{~cm}$ deep whereas subsurface drip irrigation results in higher moisture at 15 than at $5 \mathrm{~cm}$ of depth. Furthermore, furrow irrigation results in more moisture at either depth $(1,37)$. Sprinkler irrigation affects the soil moisture that can influence the inoculum spread in soil. By splashing water droplets and then possibly delivering the zoospores of $O$. brassicae throughout the field, sprinkler irrigation could result in severe LBV incidence. Subsurface drip irrigation could cause less disease due to the localized water distribution, and furrow irrigation is likely intermediate between sprinkler and subsurface drip irrigation. Sprinkler irrigation appears to result in higher incidence and subsurface irrigation is suggested to reduce the losses due to LBV disease, although further studies may be required to precisely document the effect of the different irrigation systems on the incidence of LBV.

Irrigation water could physically move inoculum propagules. In a furrow irrigation system, the water floods the furrows and the top surface of beds, and resting spores or zoospores of $O$. brassicae can be moved freely along the furrow. In contrast, $O$. brassicae seldom moves across beds. This would lead to a random or uniform distribution of the vector along the furrows, depending on the concentration of the vector, but result in an aggregated distribution across the rows. Both autocorrelation and geostatistical analyses supported this hypothesis. The semivariance within rows did not change but dramatically changed across rows in most fields. In a sprinkler irrigation system, the water is splashed onto the soil surface within a circular pattern from each spray nozzle, which splashes the soil and vector in the local area. This irrigation method is expected to result in a random spatial pattern of disease incidence. No unique distribution trend was found in fields under subsurface drip irrigation. Possibly this was because the water under the soil surface moves only locally, for a short distance by capillary action, and does not affect the physical distribution of the vector. In fact, our results supported this scenario. Thus, the natural occurrence of LBV inoculum in the field could be different, either aggregated or randomly distributed, depending on the spread by tillage and other agricultural operations.

In fields such as SPK01, sprinkler irrigation is used to cool down the temperature of lettuce plants in hot weather. This treatment favors a high disease incidence and expression, because severe symptoms and rapid translocation of the pathogen in plants are favored by cool temperatures $(36,38)$. This, along with the splashing, can explain the effect of sprinkler irrigation on LBV incidence distribution.

Spatial analyses using different statistical methods did not produce identical results for all the data sets. For instance, disease in plot GZL02 was randomly distributed, as indicated by the aggregation index $\theta$, whereas it appeared aggregated when $D$ and $Z$ indices were applied. However, by using several indices or methods, a consensus conclusion can be drawn on the type of pattern the data tend to fit.

In this study, significant differences in disease incidence among the fields with three irrigations were not detected, due to the limited data set and large variation among fields. Because the data set for each type of irrigation was small, along with the variable locations and seasons, the differences were not statistically significant. Therefore, the association of irrigation method and disease incidence needs further investigation. Different soil types vary in water-holding capacity. All of these factors consequently could influence soil moisture and vector behavior and, thus, the disease incidence pattern of the current or following seasons, complicating the analyses. Low disease incidence is probably one of the reasons for the variation of spatial patterns in the subsurface drip field. Furthermore, the sprinkler irrigation practiced in lettuce production until thinning may play a role in the vector distribution, and the subsequent irrigation methods adapted for the remainder of the season in individual fields may play a significant role in determining the level of disease incidence.
In summary, the spatial pattern of LBV disease incidence is affected by irrigation methods to some degree but not always, and the degree of aggregation observed is dependent on the quadrat size analyzed.

\section{Acknowledgments}

We thank B. Wintermantel for providing a presubmission review and the many grower cooperators who accommodated our request for data collection in their commercial fields.

\section{Literature Cited}

1. Bell, A. A., Liu, L., Reidy, B., Davis, R. M., and Subbarao, K. V. 1998 Mechanisms of subsurface drip irrigation-mediated suppression of lettuce drop caused by Sclerotinia minor. Phytopathology 88:252-259.

2. Bos, L., and Huijberts, N. 1990. Screening for resistance to big vein disease of lettuce (Lactuca sativa). Crop Prot. 9:446-452.

3. Café Filho, A. C., and Duniway, J. M. 1996. Effect of location of drip irrigation emitters and position of Phytophthora capsici infections in roots on Phytophthora root rot of pepper. Phytopathology 86:1364-1369.

4. Campbell, C. L., and Noe, J. P. 1985. The spatial analysis of soilborne pathogens and root diseases. Annu. Rev. Phytopathol. 23:129-148.

5. Campbell, R. N. 1985. Longevity of Olpidium brassicae in air-dry soil and the persistence of the lettuce big-vein agent. Can. J. Bot. 63:2288-2289.

6. Campbell, R. N., Greathead, A. S., and Westerlund, F. V. 1980. Big vein of lettuce-infection and methods of control. Phytopathology 70:741-746.

7. Campbell, R. N., and Grogan, R. G. 1963. Big-vein virus of lettuce and its transmission by Olpidium brassicae. Phytopathology 53:252-259.

8. Chellemi, D. O., Rohrbach, K. G., Yost, R. S., and Sonoda, R. M. 1988. Analysis of the spatial pattern of plant pathogens and diseased plants using geostatistics. Phytopathology 78:221-226.

9. Colariccio, A., Chaves, A. L. R., Eiras, M., Chagas, C. M., Lenzi, R., and Roggero, P. 2003. Presence of lettuce big-vein disease and associated viruses in a subtropical area of Brazil. Plant Pathol. 52:792-792.

10. Englund, E., and Sparks, A. 1991. Geostatistical Environmental Assessment Software, User's Guide. U.S. Environmental Protection Agency, Las Vegas, NV.

11. Fujii, H., Sasaya, T., Takezaki, A., Ishikawa, K., and Fujino, M. 2003. Resistance to lettuce big-vein disease in lettuce cultivars. J. Jap. Soc. Hortic. Sci.72:315-317.

12. Gottwald, T. R., Richie, S. M., and Campbell, C. L. 1992. Lcor2-spatial correlation-analysis software for the personal computer. Plant Dis. 76:213215.

13. Hao, J. J., Subbarao, K. V., and Falk, B. 1996. Spatial analyses of lettuce big-vein disease under different irrigation systems. (Abstr.) Phytopathology 86:S14.

14. Hayes, R. J., and Ryder, E. J. 2007. Introgression of novel alleles for partial resistance to big vein disease from Lactuca virosa into cultivated lettuce. HortScience 42:35-39.

15. Hayes, R. J., Wintermantel, W. M., Nicely, P. A., and Ryder, E. J. 2006. Host resistance to Mirafiori lettuce big-vein virus and Lettuce big-vein associated virus and virus sequence diversity and frequency in California. Plant Dis. 90:233-239.

16. Hughes, G., and Madden, L. V. 1993. Using the beta-binomial distribution to describe aggregated patterns of disease incidence. Phytopathology 83:759-763.

17. Hughes, G., and Madden, L. V. 1995. Some methods allowing for aggregated patterns of disease incidence in the analysis of data from designed experiments. Plant Pathol. 44:927-943.

18. Isaaks, E. H., and Srivastava, R. M. 1988. Spatial continuity measures for probabilistic and deterministic geostatistics. Math. Geol. 20:313-341.

19. Jagger, I. C., and Chandler, N. 1934. Big vein, a disease of lettuce. Phytopathology 24:1253-1256.

20. Larkin, R. P., Gumpertz, M. L., and Ristaino, J. B. 1995. Geostatistical analysis of Phytophthora epidemic development in commercial bell pepper fields. Phytopathology 85:191-203.

21. Latham, L. J., Jones, R. A. C., and McKirdy, S. J. 2004. Lettuce big-vein disease: sources, patterns of spread, and losses. Aust. J. Agric. Res. 55:125130 .

22. Lecoustre, R., Fargette, D., Fauquet, C., and Dereffye, P. 1989. Analysis and mapping of the spatial spread of African cassava mosaic-virus using geostatistics and the kriging technique. Phytopathology 79:913-920.

23. Lot, H., Campbell, R. N., Souche, S., Milne, R. G., and Roggero, P. 2002. Transmission by Olpidium brassicae of Mirafiori lettuce virus and Lettuce big-vein virus, and their roles in lettuce big-vein etiology. Phytopathology 92:288-293.

24. Madden, L. V., and Hughes, G. 1994. BBD-computer software for fitting the beta-binomial distribution to disease incidence data. Plant Dis. 78:536540.

25. Madden, L. V., and Hughes, G. 1995. Plant-disease incidence-distribution, heterogeneity, and temporal analysis. Annu. Rev. Phytopathol. 33:529-564.

26. Madden, L. V., Nault, L. R., Murral, D. J., and Apelt, M. R. 1995. Spatial pattern analysis of the incidence of aster yellows disease in lettuce. Res. 
Popul. Ecol. 37:279-289.

27. Mirkov, T. E., and Dodds, J. A. 1985. Association of double-stranded ribonucleic-acids with lettuce big vein disease. Phytopathology 75:631-635.

28. Munkvold, G. P., Duthie, J. A., and Marois, J. J. 1993. Spatial patterns of grapevines with Eutypa dieback in vineyards with or without perithecia. Phytopathology 83:1440-1448.

29. Nelson, S. C., Marsh, P. L., and Campbell, C. L. 1992. 2DCLASS, a 2dimensional distance class analysis software for the personal computer. Plant Dis. 76:427-432.

30. Pannatier, Y. 1996. VARIOWIN: Software for Spatial Data Analysis in 2D. Springe-Verlag, New York.

31. Roggero, P., Ciuffo, M., Vaira, A. M., Accotto, G. P., Masenga, V., and Milne, R. G. 2000. An ophiovirus isolated from lettuce with big-vein symptoms. Arch. Virol. 145:2629-2642.

32. Rosales, I. M., Sepulveda, P., and Bruna, A. 2004. First report of lettuce big-vein virus and Mirafiori lettuce virus in Chile. Plant Dis. 88:1286-1286.

33. Ryder, E. J. 1997. Origin and history of lettuce. Pages 1-8 in: Compendium of Lettuce Diseases. R. M. Davis, K. V. Subbarao, R. N. Raid, and E. A. Kurtz, eds. American Phytopathological Society, St. Paul, MN.

34. Ryder, E. J., and Robinson, B. J. 1995. Big-vein resistance in lettuceidentifying, selecting, and testing resistant cultivars and breeding lines. J. Am. Soc. Hortic. Sci. 120:741-746.
35. Sasaya, T., Ishikawa, K., and Koganezawa, H. 2001. Nucleotide sequence of the coat protein gene of Lettuce big-vein virus. J. Gen. Virol. 82:1509-1515.

36. Subbarao, K. V., and Davis, R. M. 1997. Crisphead lettuce growth stages. Page 7 in: Compendium of Lettuce Diseases. R. M. Davis, K. V. Subbarao, R. N. Raid, and E. A. Kurtz, eds. American Phytopathological Society, St. Paul, MN.

37. Subbarao, K. V., Hubbard, J. C., and Schulbach, K. F. 1997. Comparison of lettuce diseases and yield under subsurface drip and furrow irrigation. Phytopathology 87:877-883.

38. Westerlund, F. V., Campbell, R. N., and Grogan, R. G. 1978. Effect of temperature on transmission, translocation, and persistence of the lettuce bigvein agent and big-vein symptom expression. Phytopathology 68:921-926.

39. Westerlund, F. V., Campbell, R. N., Grogan, R. G., and Duniway, J. M. 1978. Soil factors affecting the reproduction and survival of Olpidium brassicae and its transmission of big vein agent to lettuce. Phytopathology 68:927-935.

40. Wu, B. M., Koike, S. T., and Subbarao, K. V. 2011. Impact of consumerdriven changes to crop production practices on lettuce drop caused by Sclerotinia sclerotiorum and S. minor. Phytopathology 101:340-348.

41. Xiao, C. L., Hao, J. J., and Subbarao, K. V. 1997. Spatial patterns of microsclerotia of Verticillium dahliae in soil and Verticillium wilt of cauliflower. Phytopathology 87:325-331 